\title{
Mixture Fraction Measurements of Diesel Sprays with Ducted Fuel Injection
}

\author{
Russell P. Fitzgerald, ${ }^{* 1}$ Kenth I. Svensson, ${ }^{1}$ and Glen C. Martin ${ }^{1}$ \\ ${ }^{1}$ Combustion \& Thermofluids, Caterpillar Inc., Mossville, IL, USA \\ ${ }^{\star}$ Corresponding author email: Fitzgerald Russell P@cat.com
}

\begin{abstract}
Unsteady, one-dimensional (1D) mixing models of mass and momentum conservation are generally sufficient to describe and predict local mixture fractions for unconstrained, free diesel jets over a wide range of ambient conditions. Nevertheless, the presence of walls, constraining boundaries, and in-cylinder motion complicates mixture formation and consequently requires complex 3D simulations and validation measurements. In this work, a laser-induced-fluorescence (LIF) technique is employed to measure heptane/nitrogen mixture fraction in a spray by seeding the fuel with toluene as a tracer. Comparisons of penetration and dispersion for reacting and non-reacting free jets confirm mixing similarity for the surrogate fuel at reduced temperatures, bolstering confidence in diagnostic application.
\end{abstract}

Ducted fuel injection (DFI), a novel mixture preparation approach that leads to lower soot in burning diesel sprays is investigated. Spatial distributions of quasi-steady mixturefraction are examined for several configurations (i.e., duct lengths and stand-off distances) and are compared with free-jet results at two ambient densities. The duct narrows the spray with little effect on centerline equivalence ratio. Inferred jet velocities increase proportionally with spray cross-sectional area reduction as governed by the size and position of the duct exit. Consequently, lift-off-length (LOL) is extended and equivalence ratios entering the hightemperature reaction zone are reduced.

\section{Keywords}

Diesel sprays, ducted fuel injection, soot, mixture fraction, laser-induced-fluorescence

\section{Introduction}

The formation of a combustible mixture of fuel and air via a high-velocity, atomizing spray is critical to clean, efficient operation of direct-injection internal combustion engines. As diesel engines rely on compression ignition and mixing-controlled combustion, knowledge and prediction of the local mixture fraction in the burning jet is of paramount concern. Single-plume jets injected into a quiescent environment are generally well-characterized and wellunderstood [1-4]. The same cannot be said for more complex situations for which multiple jets interact with themselves, the piston, constraining surfaces, or in-cylinder flows. Spray visualization and mixture fraction measurements can elucidate such effects and serve as critical model validation data.

Ducted-fuel-injection is a relatively new mixture formation strategy (pictured in Figure 1) for direct-injection compression ignition engines that produces demonstrably lower soot for some conditions [5]. Various investigators [5-7] have posited theories and proffered evidence for apparently enhanced mixing in the vicinity of the flame lift-off length; however, direct mixture fraction measurements have not yet been reported. Consequently, a consensus on the primary soot reduction mechanism has not been reached. This work aims to clarify several effects of DFI via the application of tracer-based fluorescence measurements of toluene/heptane (a diesel fuel surrogate) mixture fraction in a quiescent nitrogen environment. 


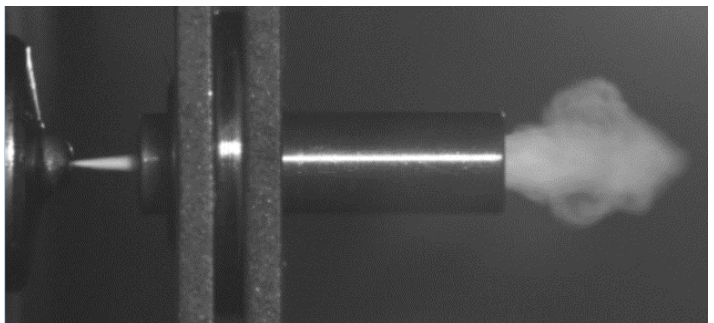

Figure 1. Common rail diesel fuel spray injected through cylindrical duct.

\section{Experimental Approach}

Spray characteristics for a common rail fuel injector with a single $137 \mu \mathrm{m}$ orifice are studied for diesel-relevant quiescent conditions in the high-temperature-pressure-vessel (HTPV) pictured in Figure 2. Vessel details and previously measured penetration and spray dispersion are described in [4] for a wide range of injection pressures and ambient densities. In this work, local mixture fraction is measured for a spray injected at $150 \mathrm{MPa}$, as it propagates unconstrainted (i.e., free jet), and while it is constrained by different circular ducts (i.e. DFI). Comparisons have been made for low $\left(25 \mathrm{~kg} / \mathrm{m}^{3}\right)$ and high $\left(50 \mathrm{~kg} / \mathrm{m}^{3}\right)$ ambient densities.

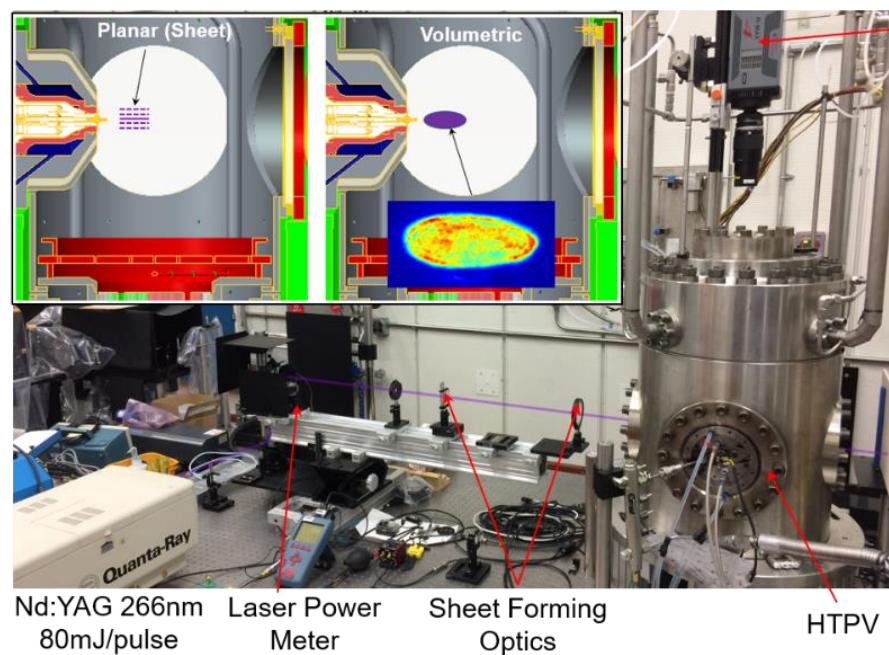

Princeton Instruments ICCD

LP295 + BP300 40nm FWHM

Figure 2. Illustration of PLIF diagnostic setup for mixture fraction measurements in the vicinity of a common rail fuel injector.
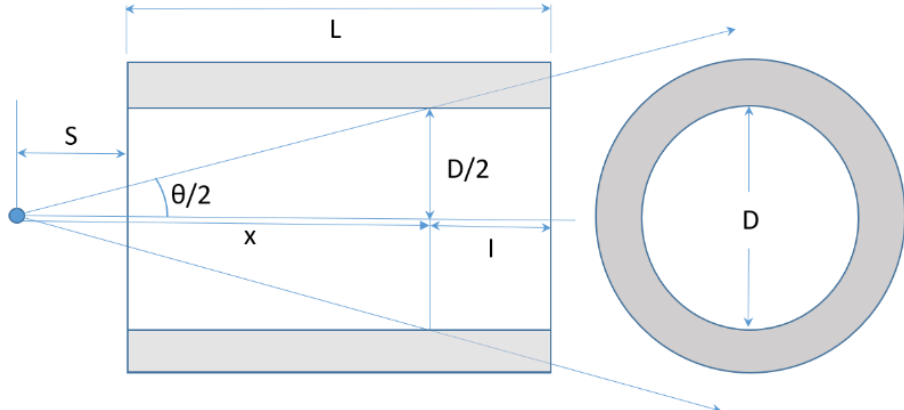

\begin{tabular}{|c|c|c|c|c|}
\hline $\begin{array}{c}\mathbf{D} \\
\text { [mm] }\end{array}$ & $\begin{array}{c}\mathbf{L} \\
{[\mathbf{m m}]}\end{array}$ & $\begin{array}{c}\mathbf{S} \\
{[\mathbf{m m}]}\end{array}$ & $\begin{array}{c}\mathbf{I} \\
{[\mathbf{m m}]}\end{array}$ & Ared [\%] \\
\hline 2 & 14 & 2 & 10.7 & 89 \\
\hline 3 & 14 & 2 & 8.1 & 76 \\
\hline 2 & 8 & 4.5 & 7.2 & 82 \\
\hline 2 & 8 & 0.1 & 2.8 & 58 \\
\hline
\end{tabular}

Figure 3. Illustration of duct geometric configuration relative to the spray, including stand-off distance (S), duct length (L), duct inner diameter (D), spray dispersion angle $(\theta)$, spray wall interaction distance (I). Effect of these parameters on spray wall interaction distance and percent area reduction are computed and tabulated for a $21.5^{\circ}$ spray angle.

Duct diameter, length, and stand-off distance (from the injector tip) are known to affect spray and diesel flame characteristics [6-7]; but, the mechanisms responsible for apparent soot variations are still under investigation. Several geometric features are examined here by considering their impact on spray-wall interaction distance and effective spray area reduction as illustrated in Figure 3. Spray-wall interaction distance, $I$, is defined as the distance along 
ICLASS 2021, $15^{\text {th }}$ Triennial International Conference on Liquid Atomization and Spray Systems, Edinburgh, UK, 29 Aug. - 2 Sept. 2021

the spray axis from the duct exit to the point at which the expanding jet first contacts the duct inner wall:

$$
I=L+S-\frac{D / 2}{\tan (\theta / 2)}
$$

for which, $L$ is the duct length, $S$ is the duct inlet stand-off distance, $D$ is the inner duct diameter, and $\theta$ is the spreading angle of the spray (which depends on ambient density). The effective spray area reduction for each duct configuration is given by a ratio of the duct exit cross-sectional area and the free jet cross-sectional area at the same point:

$$
A_{\text {red }}[\%]=100\left[1-\left(\frac{D}{2(L+S) \tan (\theta / 2)}\right)^{2}\right]
$$

These spray-wall interaction parameters are tabulated in Figure 3 for a $21.5^{\circ}$ spreading angle, which is typical for this orifice size when injecting into low $\left(25 \mathrm{~kg} / \mathrm{m}^{3}\right)$ ambient density. As inner duct diameter decreases, or duct stand-off distance increases, more of the spray is intercepted by the duct wall, thereby increasing both interaction parameters. The primary objective of this work is to understand how these duct configuration and spray-wall interaction parameters affect mixing, mean jet velocity, lift-off length, and soot for quiescent conditions.

\section{Diagnostic Approach}

Fuel tracer laser induced fluorescence (LIF) is employed to accurately measure local mixture fraction for a common rail fuel spray at conditions similar to the Engine Combustion Network (ECN) diesel reference ambient, i.e. $900 \mathrm{~K}$ and $25 \mathrm{~kg} / \mathrm{m}^{3}$ [8]. As diesel is a complex mixture of thousands of components, a simpler n-heptane/toluene (99/1 vol\%) binary mixture was selected as a surrogate for several reasons. Both are normally occurring diesel components that co-evaporate, i.e., with similar boiling points from $371-384 \mathrm{~K}$, which is critical for measurement accuracy. Toluene tracer fluorescence has an easily accessible excitation (absorption) band near $266 \mathrm{~nm}$ and well-established photo-physics [9]. Lower fuel density and boiling points for the surrogate mixture compared with diesel demands that measurements be performed in a $650 \mathrm{~K}, 4.3 \mathrm{MPa}$ pure nitrogen environment to achieve ambient density, evaporation rates, and liquid lengths similar to the ECN reference condition. Oxygen was removed to avoid complications with fluorescence signal quenching.

The optical setup used for tracer excitation and fluorescence detection is shown in Figure 2. Excitation is accomplished via $266 \mathrm{~nm}$ UV light produced from the $4^{\text {th }}$ harmonic of a Nd:YAG laser that is formed into a sheet $(1 \mathrm{~mm} \times 37 \mathrm{~mm})$. Laser energy was limited to $\sim 80 \mathrm{~mJ} /$ pulse to ensure sufficient signal while avoiding optical surface flare observed by other investigators for fluences exceeding $300 \mathrm{~mJ} / \mathrm{mm}^{2}$ [10]. A larger region of the fuel jet was probed by raster scanning the sheet via translation of the sheet forming optics. The ensuing fluorescence is filtered (LP295 and BP400, 40nm FWHM) and collected by a $105 \mathrm{~mm}$ (f/4.5) Nikon UV lens coupled to a Princeton Instruments ICCD (PI-Max4 1024i) mounted normal to the laser sheet above the HTPV.

An iterative post-processing algorithm is required to determine local fuel mixture fraction and equivalence ratio from the background subtracted ensemble mean of fluorescence images acquired during quasi-steady injection. Each ensemble consists of 25 shots acquired from individual injections separated by 30 second intervals. The detected fluorescence signal, F, is known to depend on the fluorescence quantum yield, $F Q Y$, the absorption cross section, $\sigma$, the local laser fluence, $E$, the number density of tracer molecules, $\chi_{\text {tracer }} N$, the laser sheet thickness, $t$, and the collection efficiency, $\eta_{c} \Omega / 4 \pi$, such that:

$$
F=\eta_{c}\left(\frac{\Omega}{4 \pi}\right)(t) \chi_{\text {tracer }} N\left(\frac{E}{h c / \lambda}\right) \sigma(\lambda, T) F Q Y\left(\lambda, T, P, \sum_{i} \chi_{i}\right)
$$


Iterative solution of (3) is required to determine local mixture fraction and temperature since they are related. As more hot nitrogen is entrained in the jet and the fuel mixture fraction declines, mixture temperature increases. This relationship is determined by an adiabatic mixing assumption:

$$
\left(1-Y_{\text {tracer }}\right) c_{p, N_{2}}\left(T_{N_{2}, a m b}-T_{\text {mix }}\right)=Y_{\text {tracer }}\left\{c_{p, f u e l}\left(T_{\text {mix }}-T_{\text {fuel,in }}\right)+H_{v a p}\right\}
$$

Local mixture fraction is first estimated from (3) by neglecting any temperature dependence of the fluorescence signal. After estimating local mixture temperature from (4), the local mixture fraction is then corrected based on the known temperature dependence of $F Q Y$ as reported by Sahoo and Miles [11]. These steps are repeated until convergence is achieved. Unknown quantities in Eq. 3 are lumped into a calibration constant, which is determined by measuring the total fluorescence from a known injected fuel mass that is volumetrically excited by an elliptical beam (see inset of Figure 2).

\section{Additional Measurements and Validation}

In addition to mixture fraction measurements, several other inferred and independently measured quantities are examined to elucidate effects of DFI. Significant insight has been gained by estimating mean jet velocities. Since local mixture fraction is measured during quasi-steady injection and mass flow rate is known (i.e. $\dot{m}=5.88 \mathrm{~g} / \mathrm{s}$ at $150 \mathrm{MPa}$ ), mean jet velocities at each axial location may be determined from continuity by radial integration of the local mixture density from the spray axis to the outer edge of the jet:

$$
\bar{V}(x)=\frac{\dot{m}}{\pi \int_{0}^{R(x)} \rho(x, r) r d r}
$$

Supplementary flame LOL and spatially integrated natural luminosity (SINL) measurements for reacting diesel sprays were acquired in previous work [7]. These indicate onset of high temperature reactions and relative quantities of hot soot, respectively. The non-reacting quantities measured in this work help shed light on these reacting spray quantities, provided they are similar. Agreement between jet penetration and spray dispersion (not shown here) for non-reacting n-heptane/toluene sprays and reacting diesel sprays confirm that evaporation and mixing similarity were indeed achieved. Comparisons of measured centerline mixture fraction with predictions from a 1-D mixing model [3] agree within 90-95\%.

\section{Results and Discussion}

Measurements of local tracer concentration are converted to local equivalence ratio and reported in Figure 4, assuming that the fuel is pure heptane injected into air to elucidate mixing effects on combustion. Coloured contours of equivalence ratio indicate a radially spreading jet that originates from the left edge of the plot. The images of the fuel tracer have been masked to exclude spurious data near the left edge of the laser sheet; measured values below an equivalence ratio of 0.005 are also excluded, i.e. set to zero and coloured black, indicating the apparent jet boundary. Closer to the injector tip where the jet is quite rich and liquid droplets are expected, the jet boundary falls radially outside of the dashed lines. As nitrogen is entrained, the jet spreads and core equivalence ratios diminish. In the far field, between 30 and $40 \mathrm{~mm}$ from the injector tip, the free jet boundary nearly coincides with overlaid dashed white lines that demark the expected steady spreading angle of $21.5^{\circ}$ for this case in which $150 \mathrm{MPa}$ fuel is injected into a $25 \mathrm{~kg} / \mathrm{m}^{3}$ ambient.

At first glance, the mixing field produced by the free jet and the $2 \mathrm{~mm}$ diameter, $14 \mathrm{~mm}$ long, $2 \mathrm{~mm}$ stand-off duct (hereafter, 2x14@2) are similar with a few notable differences. Downstream of the duct exit, the DFI mixture is still quite heterogeneous. Constrained by 
the duct, the spray is slightly narrower (by more than $1 \mathrm{~mm}$ ) and the core is richer as evidenced by the $\varphi=3$ contour extending $5 \mathrm{~mm}$ further downstream for the 2x14@2 configuration. With a more modest spray area reduction ratio, the $3 \times 14 @ 2$ jet is not as narrow and the mixture fraction field approaches that of the free jet.
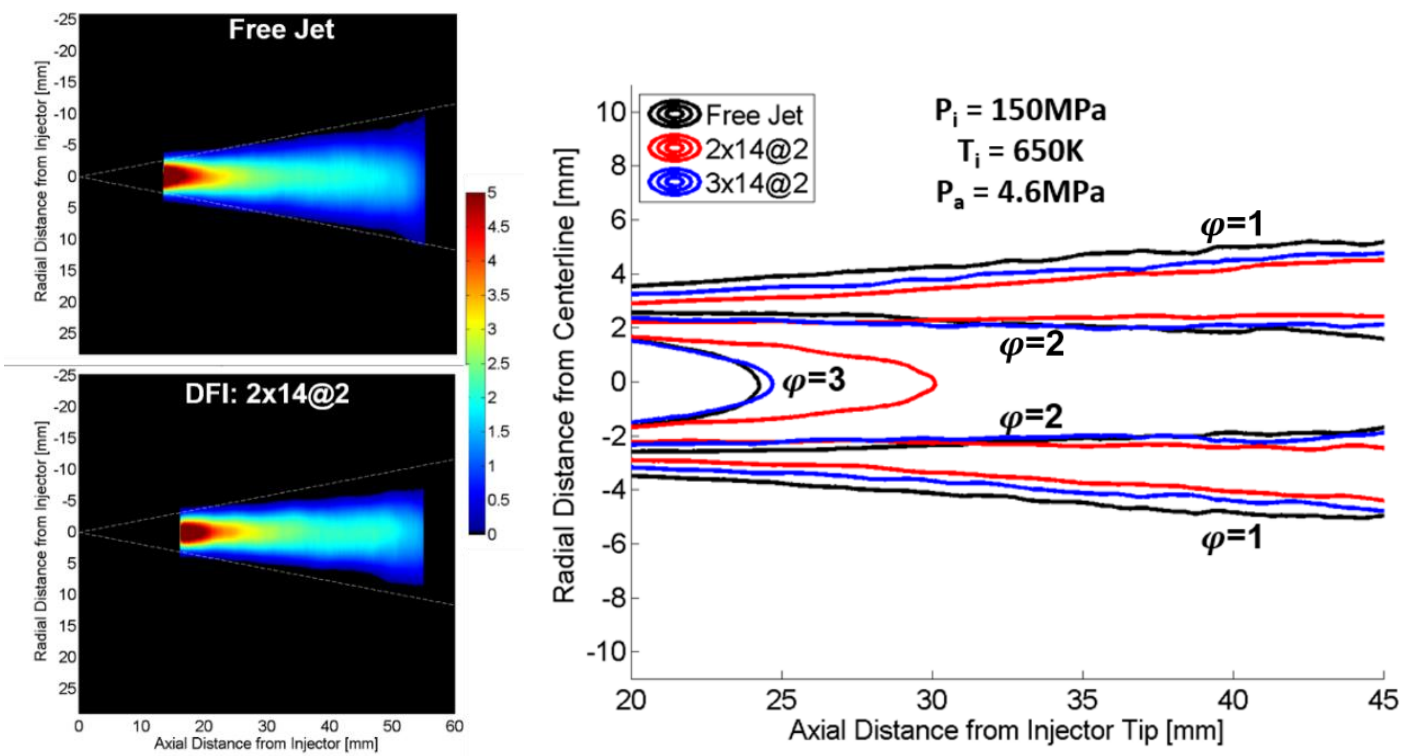

Figure 4. Comparisons of local equivalence ratio fields for a free jet with those for different duct inner diameters. Mean values computed from 25-shot measured mixture fraction ensembles are plotted individually (left). Overlays of equivalence ratio contours are shown on the right for sprays injected at $150 \mathrm{MPa}$ into low ambient density $\left(25 \mathrm{~kg} / \mathrm{m}^{3}\right)$.

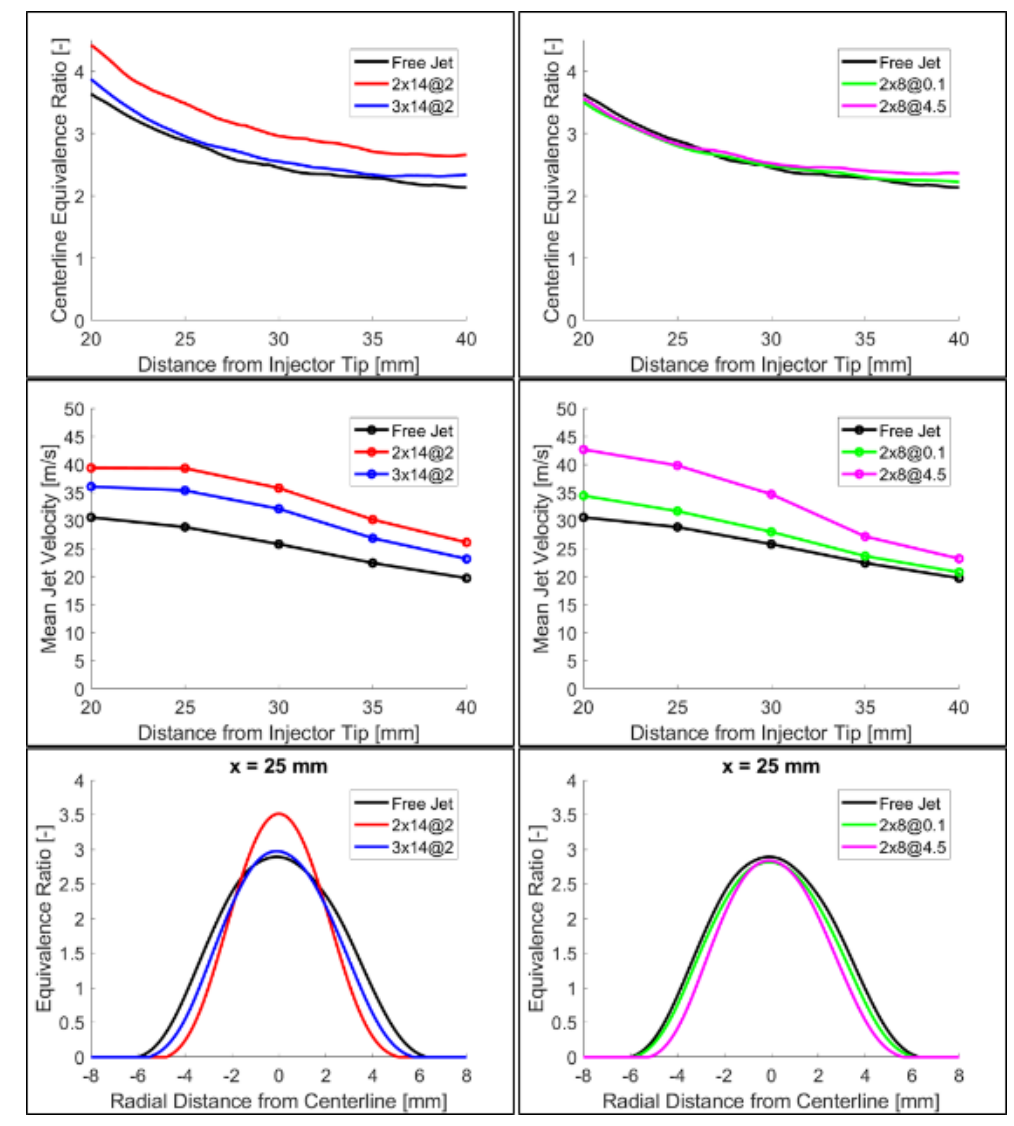

Figure 5. Effects of inner duct diameter (left) and duct stand-off distance (right) illustrated by comparisons of axial (top) and radial (bottom) equivalence ratio distributions and mean jet velocity (middle) for sprays injected at $150 \mathrm{MPa}$ into $25 \mathrm{~kg} / \mathrm{m}^{3}$. 
Comparisons of equivalence ratio variations along the jet centerline and radial mixture fraction distributions (at a distance of $25 \mathrm{~mm}$ from the injector tip) in Figure 5 illustrate that decreasing duct stand-off distance has a similar effect as increasing inner duct diameter. With the longest stand-off distance, the 2x8@4.5 spray has the second highest area reduction ratio (see Figure 3), the second richest core equivalence ratio (from 30-40 mm), and the second narrowest spray. As the stand-off distance is reduced for the 2x8@0.1 configuration, the mixture fraction field is nearly identical to the free jet.

Although the inclusion of a duct has only a modest effect on the mixture fraction distribution, a more pronounced effect on mean jet velocity is observed in the middle of Figure 5. For all DFI configurations, local mean jet velocities are higher than the free jet. Differences are most pronounced nearest the duct exit where the estimated velocity for the 2x14@2 duct is about $45 \%$ higher. It is worth noting that closer to the injector tip $(x=20-25 \mathrm{~mm})$, spurious fluorescence/phosphorescence signal from persisting liquid droplets can cause the fuel mixture fraction to be over-measured, and thus, inferred mean jet velocities are slightly lower than anticipated. All cases exhibit an expected decay in mean velocity with axial distance as the jets expand. Nevertheless, higher velocities for DFI apparently persist (and diminish) in the far-field. In previous work [4-6], higher mean jet velocities for DFI were evident from comparisons of jet vapor penetration. Figure 6 illustrates that the jet area reduction accomplished by the inner duct walls is the primary cause of increasing mean jet velocity whether by decreasing duct diameter or increasing duct stand-off distance. These trends are evident even at higher ambient densities for which jet velocities are lower.

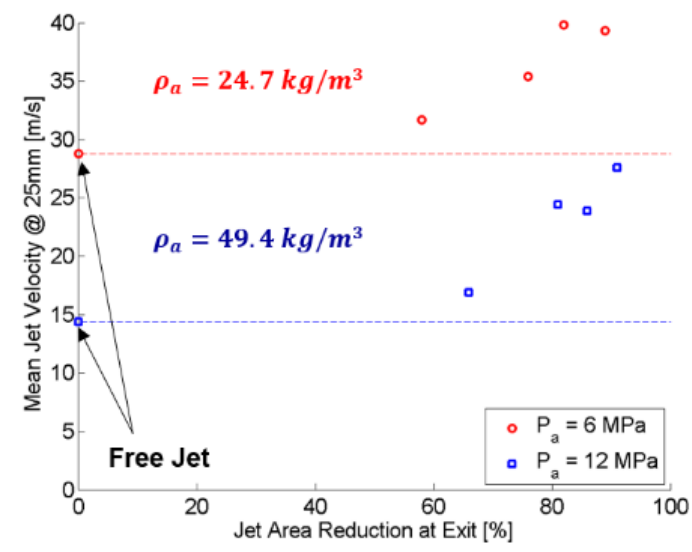

Figure 6. Trends in mean jet velocity with jet area reduction for low and high ambient density. Dashed lines indicate free jet mean velocity levels.

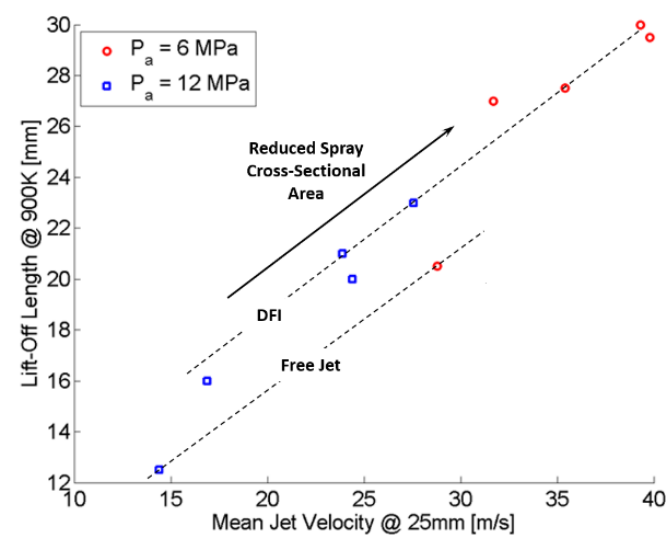

Figure 7. Measured trends in flame lift-off length with mean jet velocity for low and high ambient density.

The primary effect of jet area reduction and higher mean jet velocities for DFI is the extension of flame lift-off length as shown in Figure 7. LOL measurements were acquired for $150 \mathrm{MPa}$ diesel injections into $900 \mathrm{~K}$ air at low and high ambient density for all free jet and DFI conditions. Plotting these against the corresponding mean jet velocities $(25 \mathrm{~mm}$ from the injector tip) measured at similar conditions in this work reveals a very clear linear correlation. At low and high ambient density, for free jets and all duct configurations tested, flame lift-off length directly depends on the mean jet velocity. The subtle upward shift in the DFI trendline to longer LOL for the same mean jet velocity suggests that initially richer, cooler core mixtures leaving the duct also contribute to LOL extension.

Extension of the flame lift-off length significantly reduces the local fuel equivalence ratios entering the high-temperature reaction zones as illustrated in Figure 8 for low ambient densities. (High ambient density comparisons are omitted here as equivalence ratio measurements at relatively short lift-off-lengths are confounded by the presence of liquid 
droplets). For the free jet case, LOL is relatively short, and the fuel core is rich with peak equivalence ratios exceeding 3.5. For DFI cases, higher mean jet velocities extend the liftoff length, thereby increasing the mixing distances prior to reaction; consequently, peak equivalence ratios and apparent soot (as indicated by SINL) are reduced as tabulated in Figure 8. All four DFI cases have peak equivalence ratios at the lift-off length between 2.6 and 2.9 and corresponding reductions in apparent soot between $39-57 \%$. These trends are consistent with past observations [12-13] that net soot production drops precipitously as equivalence ratio tends toward two. That the percent SINL reductions tabulated in Figure 8 are not strictly ordered by core equivalence ratio trends is not necessarily disconcerting since soot production also depends on time and temperature history, which is not rigorously captured here. It is also worth noting that SINL does not necessarily indicate net soot production, particularly for optically thick conditions or circumstances for which soot oxidation rates are significant.

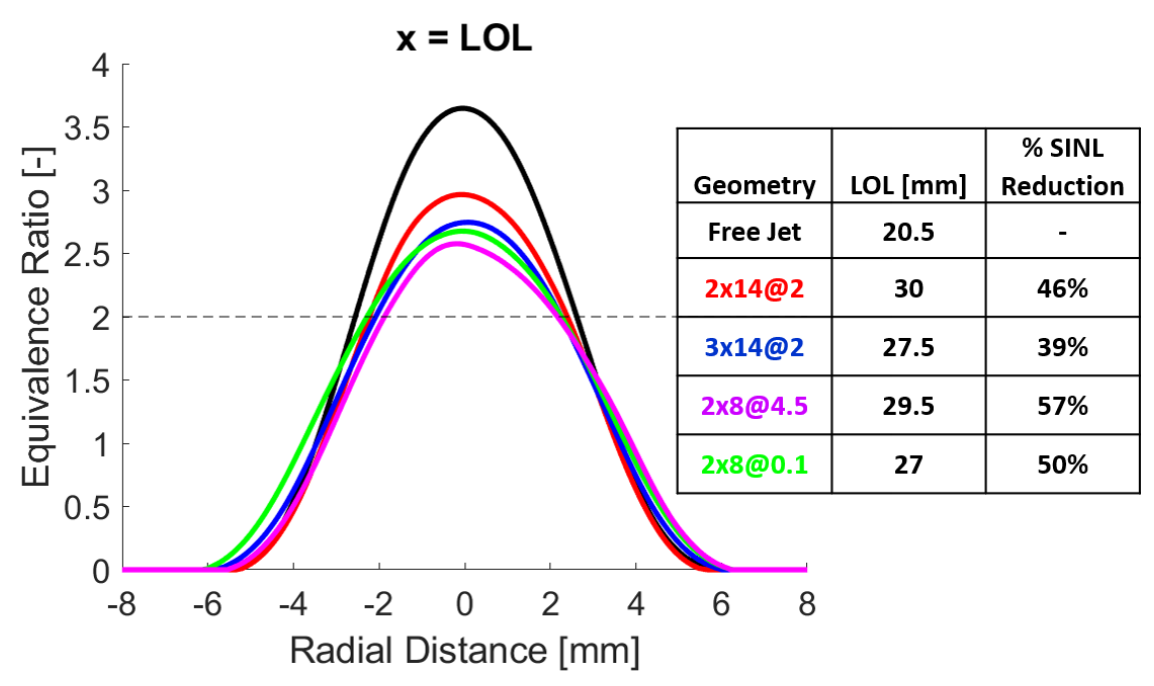

Figure 8. Comparisons of measured radially varying equivalence ratio near the flame lift-off length for a free jet and various duct configurations at low ambient density. Duct diameter and stand-off distance effects are compared on the left and right, respectively.

\section{Conclusions}

A fuel tracer (toluene) LIF technique for measuring local mixture fraction and equivalence ratio has been applied to study injection of heptane in nitrogen at diesel-similar injection conditions. Measurement accuracy has been improved by correcting for local laser fluence and mixture temperature to account for variations in fluorescence quantum yield. Measured mixture fraction compares well with free jet values predicted by a 1-D mixing model.

Subsequent measurements of local mixture fraction reveal that various DFI configurations have only a modest impact on local equivalence ratios; i.e., sprays downstream of the duct exit are slightly narrower with a richer core for a few cases. There is little evidence that mixing is enhanced within the duct as the exiting mixture is still quite heterogeneous. If considered alone, these observations could be baffling given the significant soot reductions that have been previously achieved with each duct configuration. Nevertheless, the primary effect of the duct is apparently a reduction in the spray cross-sectional area that manifests as higher mean jet velocities and longer lift-off lengths. For a wide variety of free jet and duct configurations (i.e. inner diameters, lengths, and stand-off distances), measured lift-off lengths exhibit a strong linear correlation with estimated mean jet velocity.

Consequently, equivalence ratios at the lift-off length, prior to high-temperature reactions are significantly leaner and apparent soot is reduced. As core equivalence ratios approach values above two, soot luminosity is reduced by more than $50 \%$. 


\section{Acknowledgments}

The authors gratefully acknowledge the financial support of Kevin Duffy and engine research at Caterpillar. This work also benefited from many fruitful discussions with colleagues from several institutions, i.e. Chad Koci and Yongli Qi from Caterpillar, Mark Musculus, Lyle Pickett, and Chuck Mueller from Sandia, and Sage Kokjohn at the University of Wisconsin ERC. Adam Dempsey's contribution of adiabatic mixing subroutines is appreciated.

\section{Nomenclature}

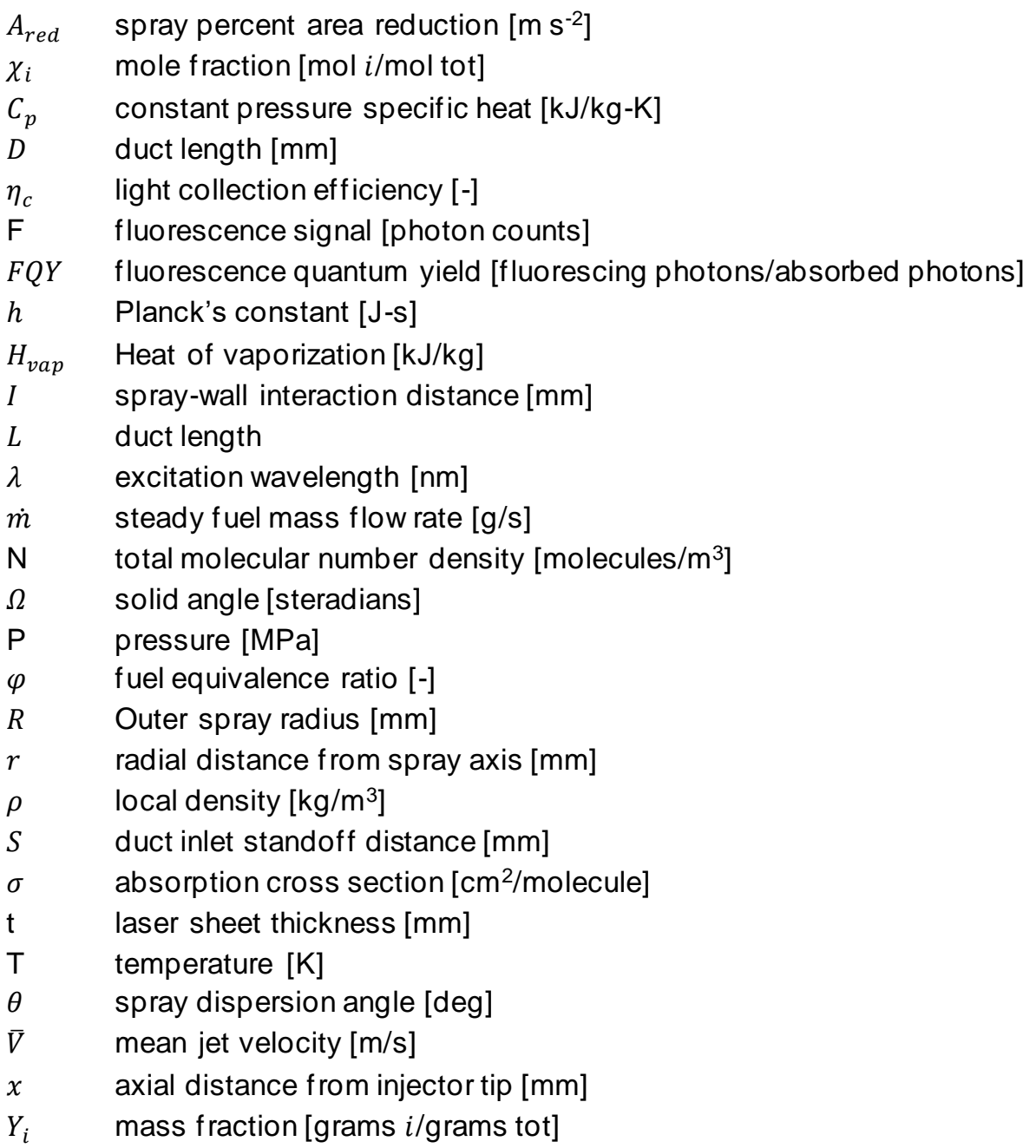

\section{References}

[1] Naber, J. and Siebers, D., 1996, SAE Technical Paper 960034.

[2] Desantes, J., Pastor, J., Payri, R., et al, 2005, Atomization and Sprays, 15 (5), pp. 517-544.

[3] Musculus, M. and Kattke, K., 2009, SAE Int. J. Engines 2(1): pp. 1170-1193.

[4] Fitzgerald, R., Gehrke, C., Svensson, K., et al, 2017, SAE Technical Paper 2017-01-0826.

[5] Mueller, C., Nilsen, C., Ruth, D., Gehmlich, R., et al., 2017, Applied Energy, 204, pp. 206-220.

[6] Fitzgerald, R., Svensson, K., Martin, G., Qi, Y., et al, 2018, SAE Int. J. Engines, 11(6), pp. 817-834.

[7] Svensson, K. and Martin, G., 2019, SAE Int. J. Adv. \& Curr. Prac. In Mobility 1(3): pp. 1074-1083.

[8] Engine Combustion Network - https://ecn.sandia.gov

[9] Koban, W., Koch, J., Hanson, R., et al., 2004, Phys. Chem. Chem. Phys., 6, pp. 2940-2945.

[10] Musculus, M., Lachaux, T., Pickett, L., et al, 2007, SAE Technical Paper 2007-01-0907.

[11] Sahoo, D., Peterson, B., Miles, P., 2011, SAE Int. J. Engines 4(2), pp. 2312-2325.

[12] Pickett, L., and D. Siebers, 2006, Int. J. Engine Res, 7, pp. 103-130.

[13] Malbec, L-M., and Kashdan, J., 2017, SAE Int. J. Engines 10(3): pp. 1064-1079. 